\title{
Calculation of Tangent Modulus of Soils under Different Stress Paths
}

\author{
Hua Huang $\mathbb{D}^{1},{ }^{1}$ Min Huang $\mathbb{D},{ }^{1}$ and Jiangshu Ding ${ }^{2}$ \\ ${ }^{1}$ School of Civil Engineering, Chang'an University, Xian 710061, China \\ ${ }^{2}$ Land, Urban Construction and Water Affairs Bureau of Chancheng District, Foshan 528000, China
}

Correspondence should be addressed to Min Huang; 1443552509@qq.com

Received 7 January 2018; Revised 11 February 2018; Accepted 5 April 2018; Published 13 May 2018

Academic Editor: Zhi-ke Peng

Copyright (c) 2018 Hua Huang et al. This is an open access article distributed under the Creative Commons Attribution License, which permits unrestricted use, distribution, and reproduction in any medium, provided the original work is properly cited.

During excavation of foundation pit, soils of different sites may undergo different unloading paths. This study focuses on the tangent modulus of soil under different stress paths and provides theoretical basis for the deformation calculation of soil. In this paper, conventional triaxial compression test and $K_{0}$ consolidation unloading test were conducted with mucky soil and silty clay to obtain the deformation characteristics of soils under different stress paths. Experiment results show that the soil samples exhibit distinct stress-strain characteristics under different stress paths, but they all show nonlinearity. The initial tangent modulus increases as the consolidation confining pressure intensifies. Then, based on the test data, the power function relationship between initial tangent modulus and confining pressure under unloading was verified. Simultaneously, a hyperbola function to express stress-strain relation of soils under the $K_{0}$ consolidation unloading condition was proposed and proved. Finally, the formulas of the tangent modulus under $K_{0}$ consolidation unloading were established referring to the derivation of that in Duncan-Chang model. The theoretical calculation results agree well with the test results. It can expand the use of the Duncan-Chang model and improve its application to engineering practice.

\section{Introduction}

Excavations alter the initial stress states of soil around the foundation pit and unavoidably have varying degrees of impacts to surrounding existing structures. Studying the mechanical characteristics of soils on different sites during deep excavation is greatly significant to its design and construction.

Many researchers have studied the mechanical characteristics of soils under different loading stress paths [1-6]. However, in practice, soils may be in a state of unloading stress path during the construction of earthen structures, such as foundations, tunnels, and pit excavations. Ng [7] pointed out that the mechanical behaviors of many soils, such as stiff clays, depend on their current effective-stress states and stress history. Other researchers [8-14] have also carried out a series of stress-path triaxial tests and verified the path dependency of soil.

To account for the deformation characteristics of soils, many models have been put forward. For example,
Jardine [15], Al-Tabbaa and Wood [16], Mair [17], and Stallebrass and Taylor [18] suggested various bounding surface models. Duncan and Chang [19] put forward the DuncanChang model. Among them, the Duncan-Chang model is the most typically and widely used, because it can not only reflect the nonlinear characteristics of soil but also be suitable for a wide range of soils. However, existing models do not take the effect of stress paths into account, and the Duncan-Chang model is only applicable to conventional triaxial tests. In practice, soils may undergo various complex stress paths that can differ greatly from conventional stress paths. Therefore, further study on such issues has been conducted. Chen et al. [20] compared the characteristics of rock salt exposed to loading and unloading of confining pressure and proposed a constitutive model of rock salt damage based on unloading theory. Masin et al. [21, 22] proposed a hypoplastic model for clays considering the influence of stress paths. However, the applicability of these models has been verified only in a few soils, limiting the range of their application. Thus, to predict the characteristics of a wide range 
of soils under complex stress state, the Duncan-Chang model was investigated and revised. For example, Chen et al. [23], $\mathrm{Li}$ [24], and He et al. [25] obtained the stress-strain relationship of soil under lateral unloading and derived the tangent modulus under lateral unloading stress path on the basis of the Duncan-Chang model. Liu et al. [26] referred to the Duncan-Chang model to develop a recursion of formulas, which shows the relationship between the stress-path condition of excavation and tangent modulus. However, the scope of the aforementioned studies is narrow. They focus mainly on the stress-strain relation and modulus formula under lateral unloading stress path. To date, studies on the stress-strain relation of soil under axial unloading are limited. In addition, few researchers systematically study the modulus formulas under different stress paths. With the increasing number of foundation pits, obtaining the tangent modulus of soil under different stress paths is important to satisfactorily predict the deformation of soil during excavation.

In this study, in order to derive the calculation formulas of tangent modulus under different stress paths, the conventional triaxial compression test and the $K_{0}$ consolidation unloading test were conducted on the representative mucky soil and silty clay. The mechanical properties of soils under different stress paths were discussed. Then, based on the test results, an equation about stress-strain relation was set up and verified. Finally, the tangent modulus of soil under different stress paths was derived, which improves the analytical precision for determining the deformation characteristics of soil during excavation.

This paper is organized as follows. Section 2 compares the mechanical properties of soils under $K_{0}$ consolidation unloading condition with that under conventional loading condition. And based on the experiment results, an equation on stress-strain relation under unloading condition is proposed and verified in this section. Meanwhile, in Section 3, the power function relation between initial tangent modulus and confining pressure under unloading condition is also verified. Section 4 presents the process of deduction for tangent modulus under unloading, and they are in good accordance with test results shown in Section 5.

\section{Mechanical Properties of Soil under Different Stress Paths}

This section details the conventional triaxial compression, lateral unloading, and axial unloading tests that were carried out on silty clay and mucky soil. Simultaneously, the stressstrain curves under different stress paths were obtained. The mechanical properties of soil under different stress paths were then analyzed. The hyperbolic relation between stress and strain under the unloading condition was proposed and verified. Then the tangent modulus of the soil under different stress path can be deduced.

2.1. Introduction of the Experiment. During the excavation of foundation pit, the physical characteristics, such as the stressstrain relation of soil, change in varying degrees. Figure 1 shows the division of areas affected during excavation to

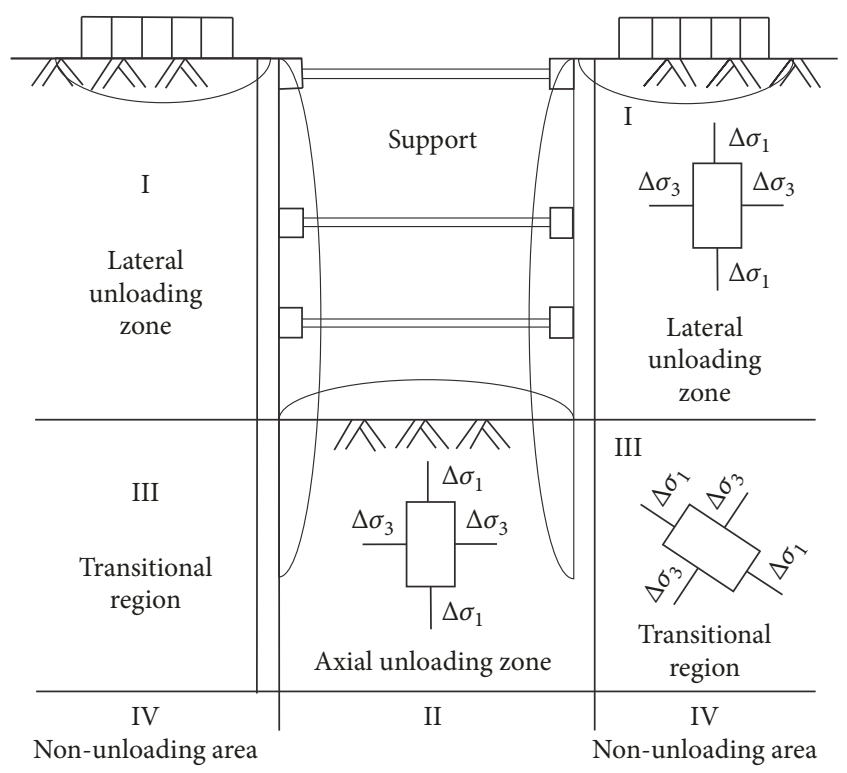

FIGURE 1: Soil stress state within the influencing scope of foundation pit.

realistically respond to and study the mechanical properties of soil after excavation. These areas are divided into four parts according to the stress paths of soil under $p-q$ stress space as shown in Figure 2.

Lateral unloading zone (I): with the excavation of the foundation pit, the stress of soil remains unchanged in the vertical direction while decreasing gradually in the horizontal direction. In this area, the mean principal stress $p$ of soil decreases, while the generalized shear stress $q$ of soil increases during excavation. Figure 2 presents the stress path of lateral unloading zone as shown by line AC. The mechanical properties of soil in this area can be studied by lateral unloading test.

Axial unloading zone (II): as the overlying soil is gradually excavated, the stress of soil remains unchanged in the horizontal direction while decreasing gradually in the vertical direction. In this area, the mean principal stress $p$ and generalized shear stress $q$ of soil decrease. Figure 2 presents the stress path of axial unloading zone as shown by line AS.

Transitional region (III): during excavation, the stress of soil in this area decreases in the horizontal and vertical directions, and the principal stress axis rotates. Figure 2 presents the stress path of transitional region shown between line AC and line AS in Figure 2.

Nonunloading area (IV): vertical stress remains constant, whereas horizontal stress obtains a minor change.

2.2. Test Apparatus. The SLB-1 stress-strain controlled triaxial shear infiltration testing apparatus was used in the experiment. Figure 3 shows its basic structure. In this experiment, silty clay and mucky soil were used as materials. By drilling the undisturbed soil at different depths, three silty and three mucky soil samples were obtained under different stress paths. The consolidation pressure adopted was 50, 100, and $200 \mathrm{kPa}$ for the consolidation stress-path test. Foundation pit engineering was a temporary project, and the test samples 


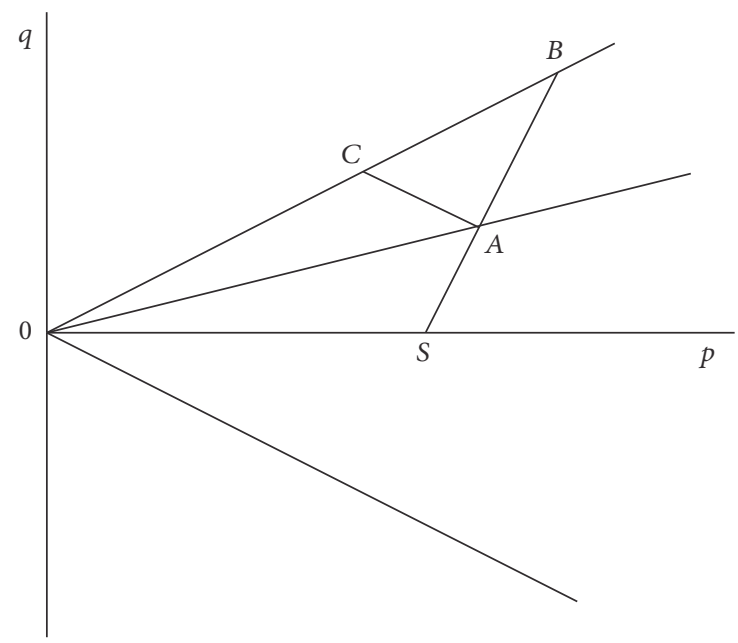

FIGURE 2: $p-q$ stress space and path.

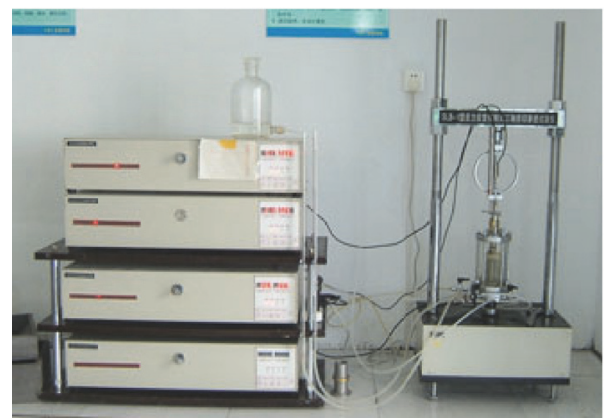

FIGURE 3: SLB-1 stress-strain controlled triaxial shear penetration apparatus.

were silty clay and mucky soil with a low permeability coefficient. Therefore, undrained conditions were adopted in the progress of the unloading test. First, to restore the stress history of soil, each sample was $K_{0}$ consolidated to the in situ stress state, and different paths were utilized in the experiment. $K_{0}$ is also called static lateral pressure coefficient, which can be approximately calculated by $K_{0}=1-\sin \varphi^{\prime} ; \varphi^{\prime}$ is the effective angle of internal friction; it can be tested by undrained conventional triaxial experiment.

2.3. Experimental Results. The stress-strain curves of silty clay and mucky soil under different stress paths were tested and illustrated in Figures 4-9. In Figures 4-9, $\sigma_{1}, \sigma_{3}$ are axial pressure and lateral pressure, separately. $\varepsilon_{1}$ denotes axial strain.

In the figures, the following conclusions can be drawn.

(1) The stress-strain curves of soil under different stress paths exhibit obvious nonlinear quality.

(2) The stress-strain curves of silty clay and mucky soil show fairly similar deformation trend.

(3) Figures 4 and 5 illustrate that, for conventional triaxial compression test, stress increases with the increase in strain in the initial stage of external loads. When stress increases to a certain value, its increasing margin rapidly slows down, while the strain increases rapidly, the curves present work

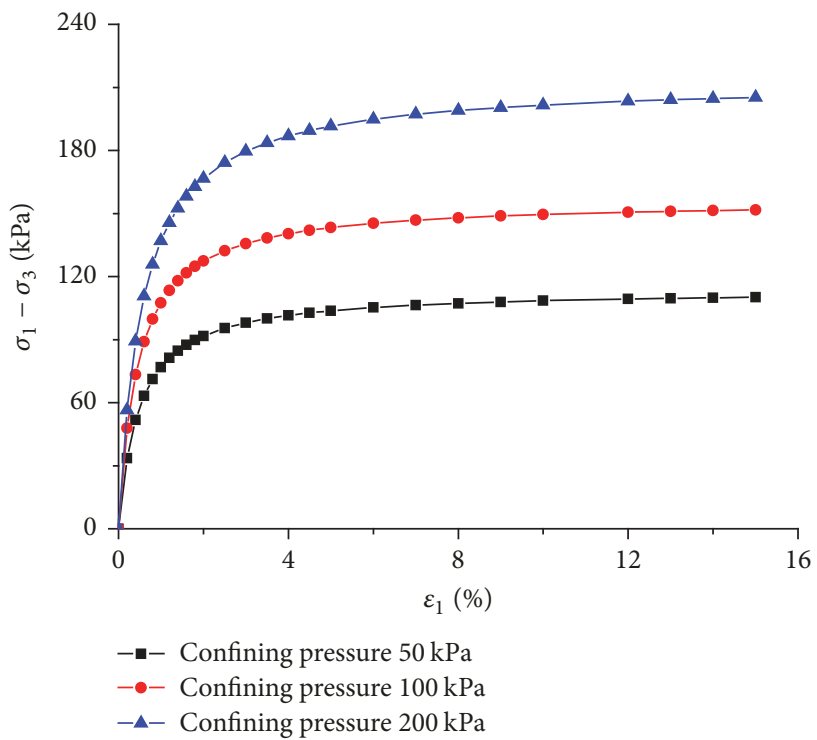

FIGURE 4: $\left(\sigma_{1}-\sigma_{3}\right)-\varepsilon_{1}$ curves of silty clay under conventional triaxial test.

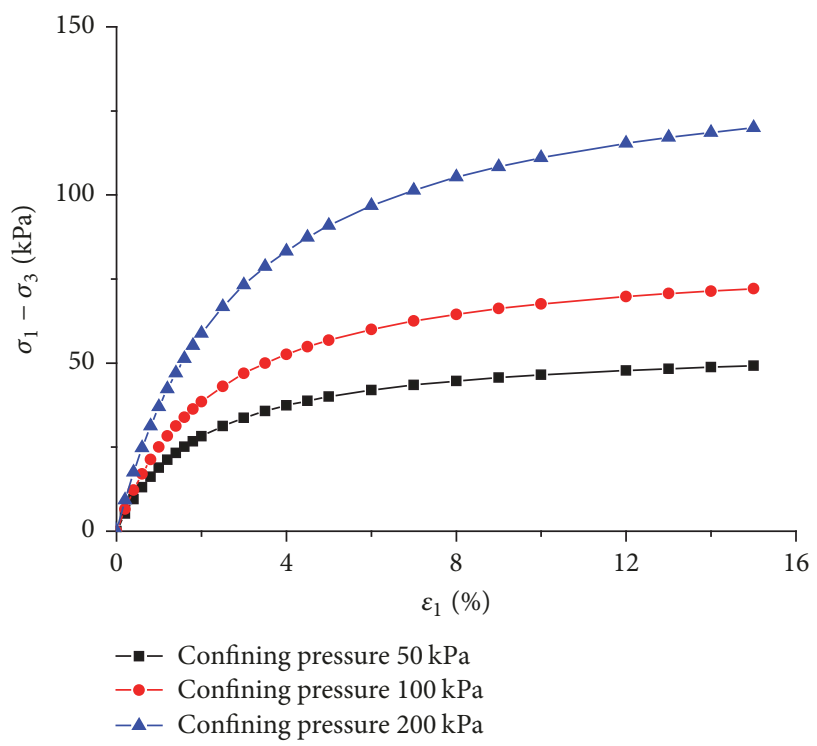

FIgURE 5: $\left(\sigma_{1}-\sigma_{3}\right)-\varepsilon_{1}$ curves of mucky soil under conventional triaxial test.

hardening. For the same type of soil samples, the stressstrain curve steepens, initial tangent modulus increases, and limiting stress increases as consolidation pressure intensifies.

(4) Figures 6 and 7 illustrate that, during lateral unloading, the peak value of the deviatoric stress increases with the increase of consolidation pressure for the same type of soil samples.

(5) Figures 8 and 9 present that, during axial unloading, the failure model of soil does not present a compression-shear failure but presents axial elongated failure. The development law of axial unloading stress-strain curves is obviously different from that of axial loading and lateral unloading stress-strain curves. 


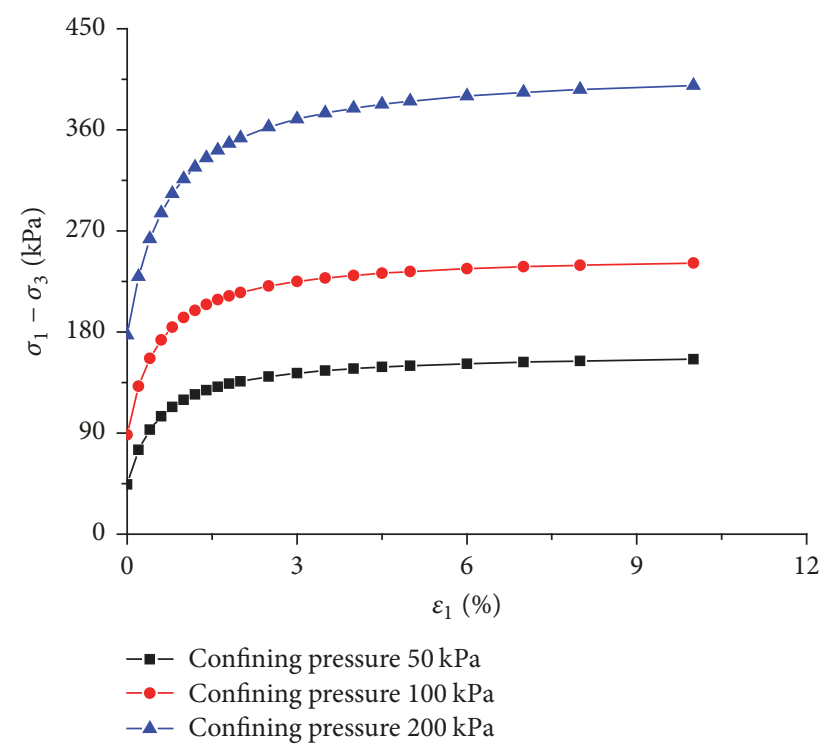

FIgURE 6: $\left(\sigma_{1}-\sigma_{3}\right)-\varepsilon_{1}$ curves of silty clay under lateral unloading.

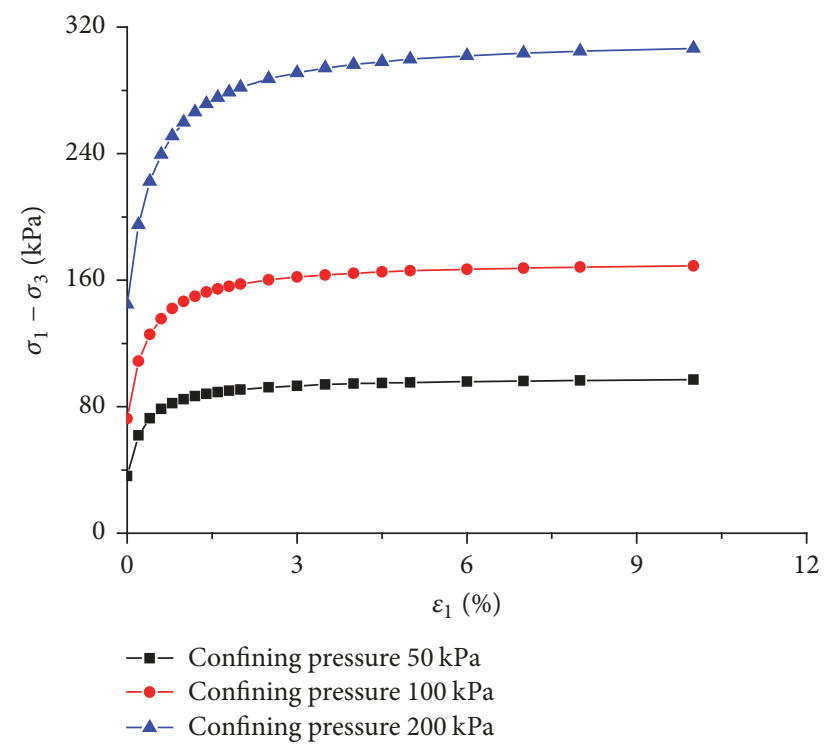

FIGURE 7: $\left(\sigma_{1}-\sigma_{3}\right)-\varepsilon_{1}$ curves of mucky soil under lateral unloading.

2.4. Verification of the Hyperbolic Relation between Stress and Strain of Soil under Unloading. Figures 4-9 show that the stress-strain relation of soil under different stress paths exhibits nonlinear quality and can approximately be modeled by hyperbolic function. In 1963, Kondner proposed a hyperbolic equation on the basis of a significant quantity of triaxial tests as follows:

$$
\sigma_{1}-\sigma_{3}=\frac{\varepsilon_{1}}{a+b \varepsilon_{1}},
$$

where parameters $a$ and $b$ are test constants.

Compared with soil under conventional isotropic consolidation, that under $K_{0}$ consolidation is not on the isotropic consolidation condition. An initial axial stress difference $\left(3\left(1-K_{0}\right) /\left(1+2 K_{0}\right)\right) \sigma_{m}$ exists; $\sigma_{m}$ is average consolidation

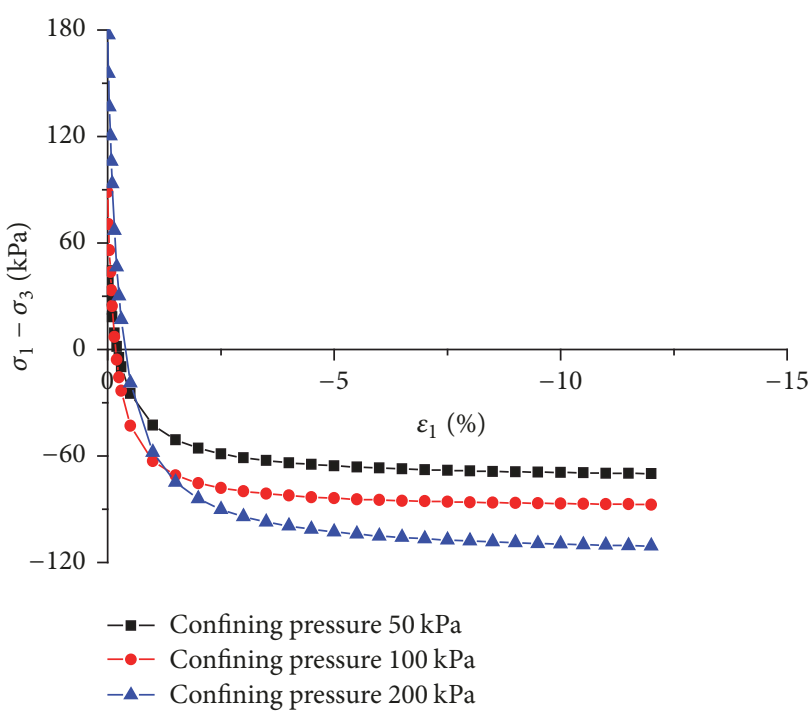

FiguRE 8: $\left(\sigma_{1}-\sigma_{3}\right)-\varepsilon_{1}$ curves of silty clay under axial unloading.

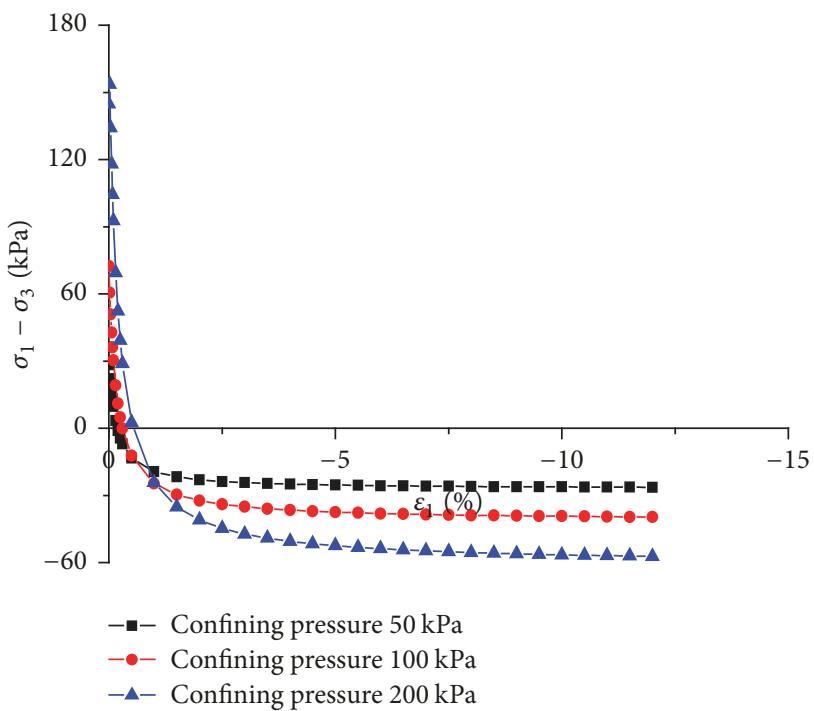

FIGURE 9: $\left(\sigma_{1}-\sigma_{3}\right)-\varepsilon_{1}$ curves of mucky soil under axial unloading.

pressure. In addition, the axial strain of the soil is related to the axial stress difference. According to the test results, stress-strain curves under the $K_{0}$ consolidation condition are similar to those under conventional isotropic consolidation condition. Consulting (1), the stress-strain relation of soil under different stress paths in the $K_{0}$ consolidation condition can be assumed to be expressed as follows:

$$
\left(\sigma_{1}-\sigma_{3}\right)-\frac{3\left(1-K_{0}\right)}{1+2 K_{0}} \sigma_{m}=\frac{\varepsilon_{1}}{a+b \varepsilon_{1}}
$$

where $a$ is the reciprocal of the initial tangent modulus, $b$ is the reciprocal of hyperbolic asymptotic values $\left(\sigma_{1}-\sigma_{3}\right)_{\text {ult }}$ $\left(3\left(1-K_{0}\right) /\left(1+2 K_{0}\right)\right) \sigma_{m}$, and $\left(\sigma_{1}-\sigma_{3}\right)_{\mathrm{ult}}$ is the deviatoric 


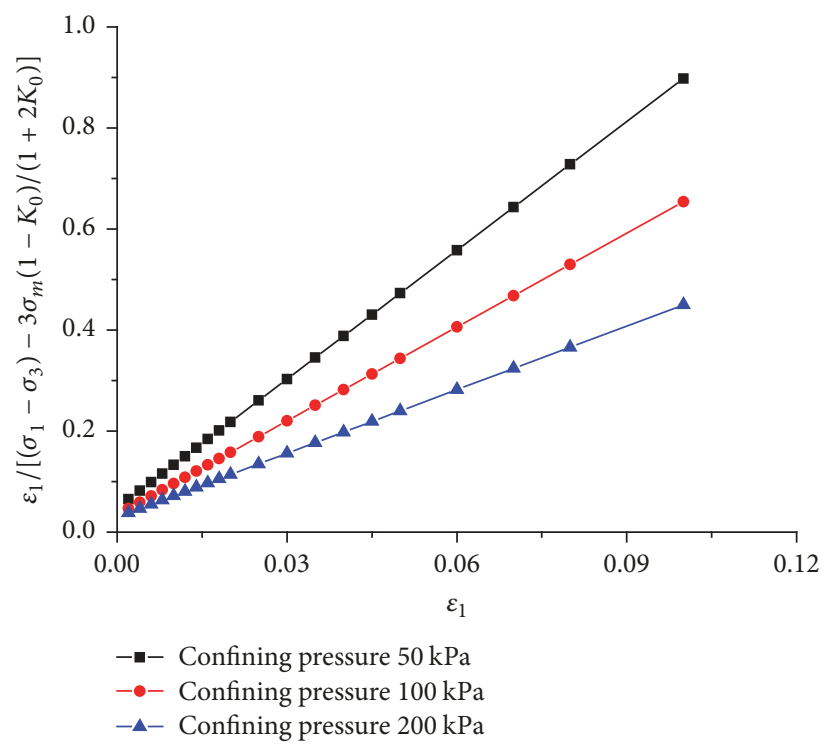

FIGURE 10: Lateral unloading relation curves of silty clay.

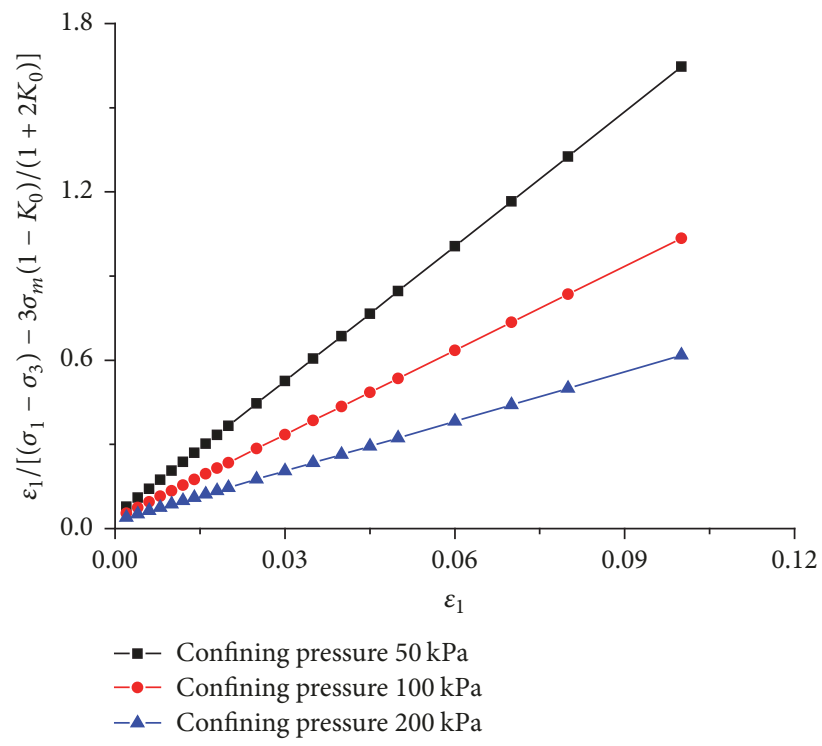

FIGURE 11: Lateral unloading relation curves of mucky soil.

stress when the strain tends to infinity. Rearranging (2), the following equation can be obtained:

$$
\frac{\varepsilon_{1}}{\left(\sigma_{1}-\sigma_{3}\right)-\left(3\left(1-K_{0}\right) /\left(1+2 K_{0}\right)\right) \sigma_{m}}=a+b \varepsilon_{1} .
$$

Taking $\varepsilon_{1}$ and $\varepsilon_{1} /\left[\left(\sigma_{1}-\sigma_{3}\right)-\left(3\left(1-K_{0}\right) /\left(1+2 K_{0}\right)\right) \sigma_{m}\right]$ as the abscissa and ordinate, respectively, the stress-strain curves in Figures 6-9 can be converted into a series of corresponding straight lines as shown in Figures 10-13. Thus, the stress-strain relation in the $K_{0}$ consolidation condition provided by (2) is verified. From (3), $a$ is the linear intercept, and $b$ denotes the line's slope.

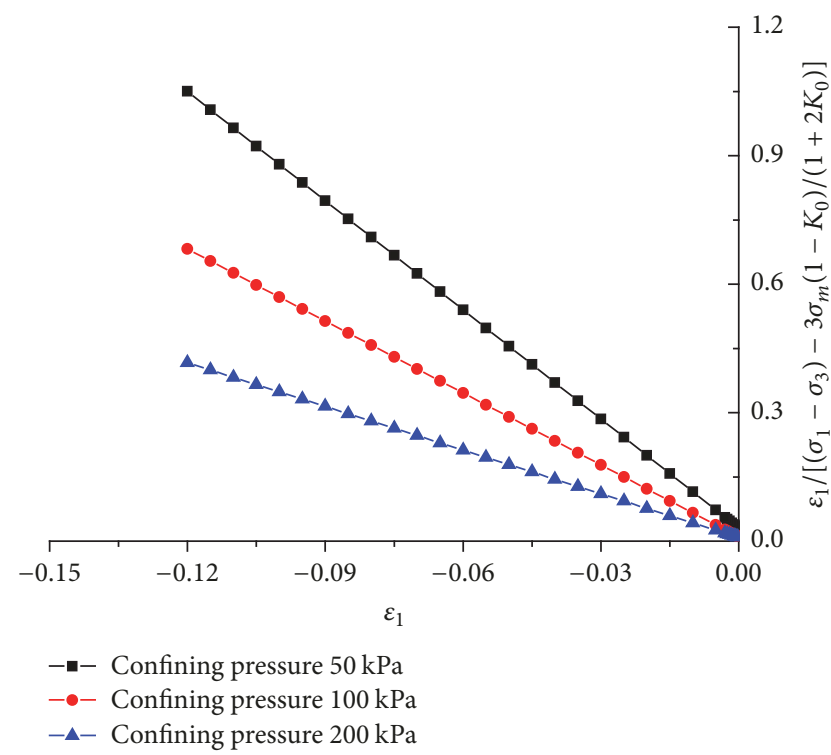

FIGURE 12: Axial unloading relation curves of silty clay.

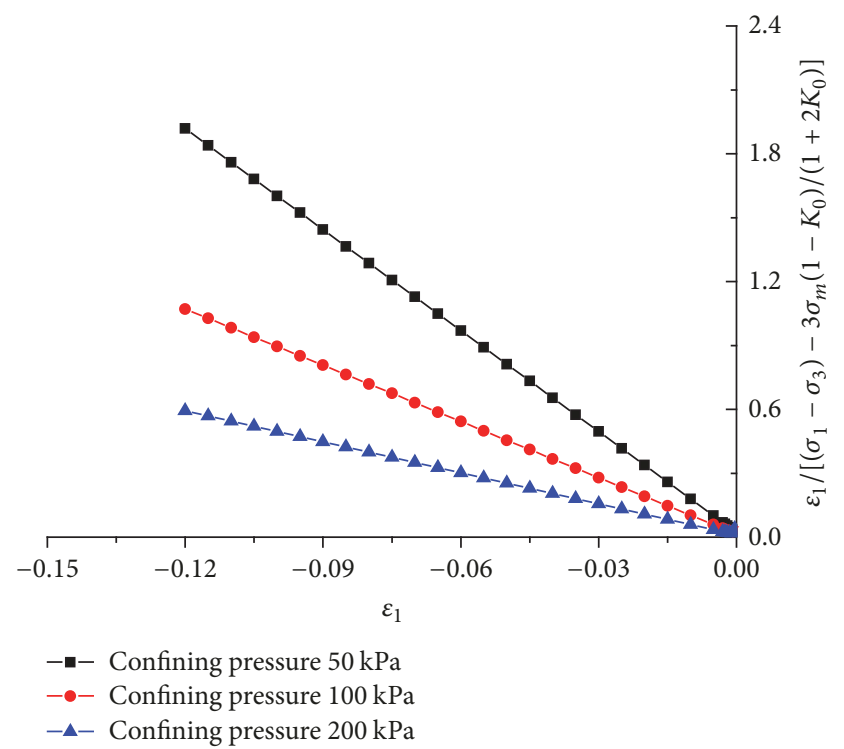

Figure 13: Axial unloading relation curves of mucky soil.

\section{Initial Tangent Modulus of Soil under Unloading Condition}

In the Duncan-Chang model, the initial tangent modulus is a key parameter. This section discusses the relationship between the initial tangent modulus and soil performance, consolidation confining pressure, and stress path. Figures 14 to 17 and Tables 1 and 2 present the results.

The following conclusions can be drawn from Figures 14-17 and Tables 1 and 2.

(1) For the same type of soil, the initial tangent modulus of soil increases with the consolidation confining pressure. In addition, the relationships between the initial tangent 
TABLE 1: Initial tangent modulus of silty clay under $K_{0}$ consolidation unloading condition.

\begin{tabular}{|c|c|c|}
\hline Silty clay & Confining pressure $\sigma_{a}(\mathrm{kPa})$ & Initial tangent modulus $E_{i}(\mathrm{kPa})$ \\
\hline \multirow{3}{*}{ Lateral unloading } & 50 & $2.08 \times 10^{4}$ \\
\hline & 100 & $2.94 \times 10^{4}$ \\
\hline & 200 & $3.33 \times 10^{4}$ \\
\hline \multirow{3}{*}{ Axial unloading } & 50 & $3.33 \times 10^{4}$ \\
\hline & 100 & $1.00 \times 10^{5}$ \\
\hline & 200 & $1.18 \times 10^{5}$ \\
\hline
\end{tabular}

TABLE 2: Initial tangent modulus of mucky soil under $K_{0}$ consolidation unloading condition.

\begin{tabular}{|c|c|c|}
\hline Mucky soil & Confining pressure $\sigma_{a}(\mathrm{kPa})$ & Initial tangent modulus $E_{i}(\mathrm{kPa})$ \\
\hline \multirow{3}{*}{ Lateral unloading } & 50 & $2.17 \times 10^{4}$ \\
\hline & 100 & $2.68 \times 10^{4}$ \\
\hline & 200 & $3.57 \times 10^{4}$ \\
\hline \multirow{3}{*}{ Axial unloading } & 50 & $4.55 \times 10^{4}$ \\
\hline & 100 & $6.67 \times 10^{4}$ \\
\hline & 200 & $1.32 \times 10^{5}$ \\
\hline
\end{tabular}

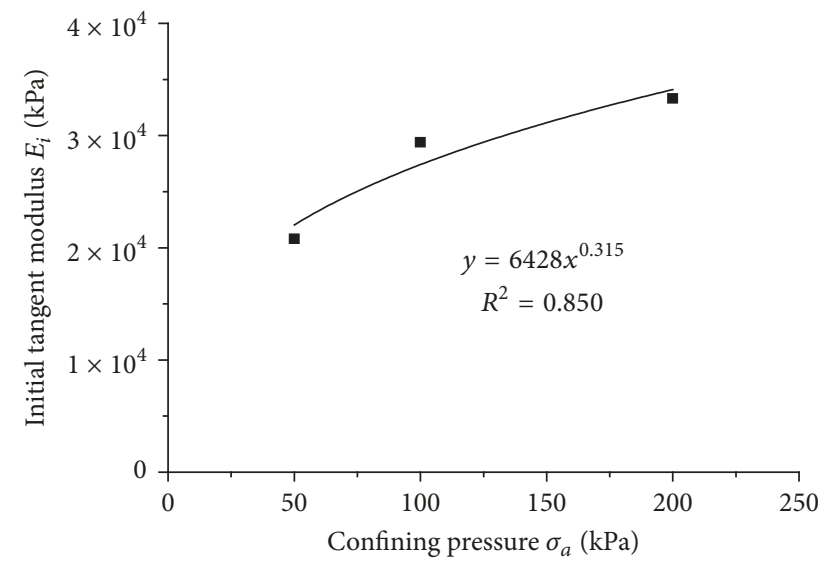

FIGURE 14: Relationship between initial tangent modulus and confining pressure of silty clay under the lateral unloading $K_{0}$ consolidation condition.

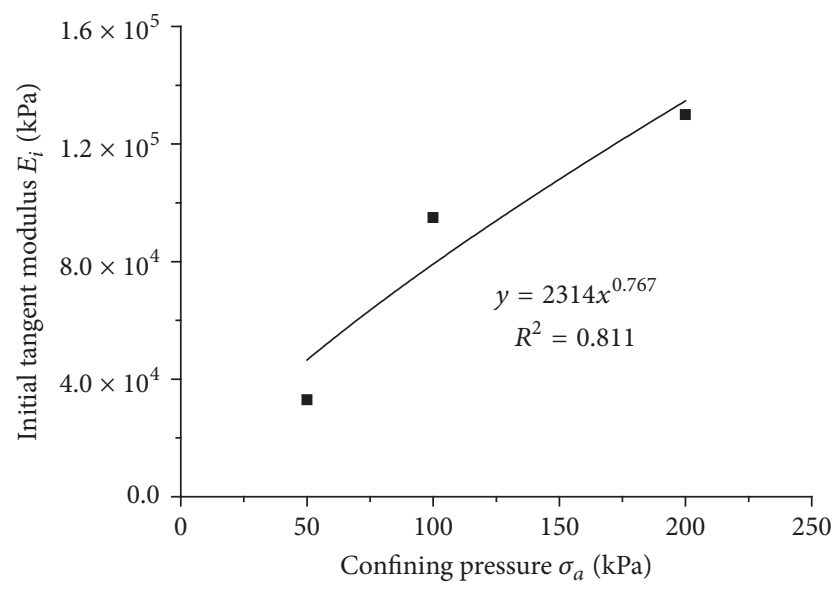

Figure 15: Relationship between initial tangent modulus and confining pressure of silty clay under the axial unloading $K_{0}$ consolidation condition.

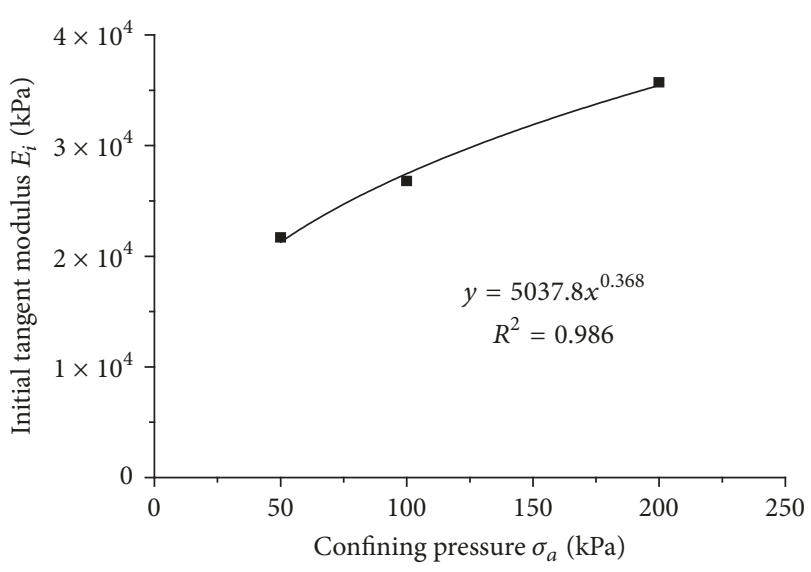

FIGURE 16: Relationship between initial tangent modulus and confining pressure of mucky soil under the lateral unloading $K_{0}$ consolidation condition.

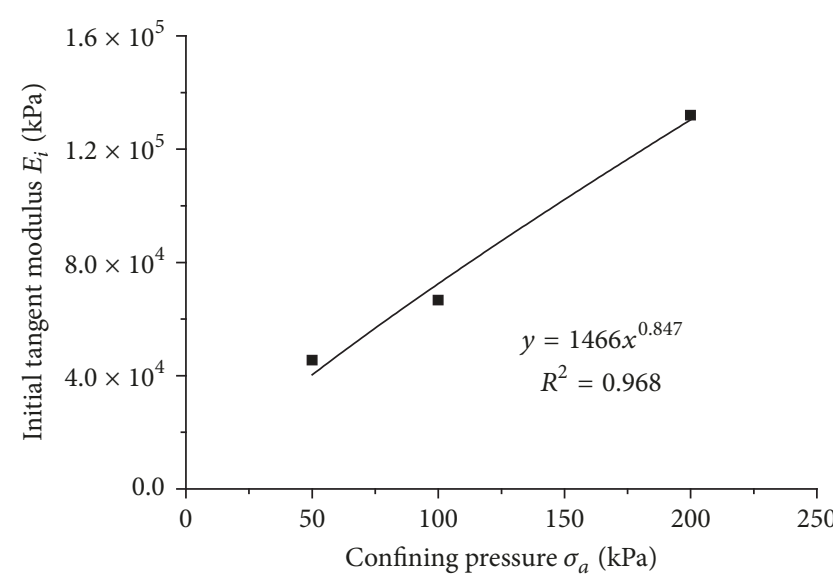

FIGURE 17: Relationship between initial tangent modulus and confining pressure of mucky soil under the axial unloading $K_{0}$ consolidation condition. 
modulus and confining pressure under unloading can be fitted with power functions.

(2) For the same type of soil, the initial tangent modulus of soil under axial unloading stress path is larger than that in lateral unloading stress path.

\section{Calculation Formula of Tangent Modulus}

Based on the previous discussion, the stress-strain curves under different stress paths can be fitted by hyperbola whereas the stress-strain functions under unloading condition vary from that under conventional loading condition. Therefore, this section deduces the calculation formulas of tangent modulus under lateral and axial unloading stress paths on the basis of the Duncan-Chang model, expanding the application of the Duncan-Chang model to engineering practice.

The slope of stress-strain curves $E_{0}$ can be calculated as follows:

$$
E_{0}=\frac{\Delta\left(\sigma_{1}-\sigma_{3}\right)}{\Delta \varepsilon_{1}}=\frac{\left(\Delta \sigma_{1}-\Delta \sigma_{3}\right)}{\Delta \varepsilon_{1}} .
$$

$\Delta \sigma_{1}, \Delta \sigma_{3}$ are axial pressure increment and lateral pressure increment, separately. $\Delta \varepsilon_{1}$ is axial strain increment.

During the excavation of the foundation pit, the stress paths of soil are usually divided into two types: axial and lateral unloading. In the case of lateral unloading, $\Delta \sigma_{1}=0$. The parameter $E_{0}$ in (4) can be expressed as follows:

$$
E_{0}=-\frac{\Delta \sigma_{3}}{\Delta \varepsilon_{1}}
$$

Based on the generalized Hooke's law, the following equations are obtained:

$$
\begin{aligned}
& \Delta \varepsilon_{3}=\frac{1}{E_{t}}\left[\Delta \sigma_{3}-\mu\left(\Delta \sigma_{3}+\Delta \sigma_{1}\right)\right] \\
& \Delta \varepsilon_{1}=\frac{1}{E_{t}}\left[\Delta \sigma_{1}-\mu\left(\Delta \sigma_{3}+\Delta \sigma_{3}\right)\right],
\end{aligned}
$$

where $E_{t}$ is the tangent modulus of soil, $\Delta \varepsilon_{3}$ is lateral strain increment, and $\mu$ is Poisson's ratio.

Comparing (6) and (7) yields the following:

$$
\begin{aligned}
E_{t} & =\frac{\left(\Delta \sigma_{1}-\Delta \sigma_{3}\right)\left(\Delta \sigma_{1}+2 \Delta \sigma_{3}\right)}{\Delta \varepsilon_{1} \Delta \sigma_{1}+\Delta \sigma_{3}\left(\Delta \varepsilon_{1}-2 \Delta \varepsilon_{3}\right)} \\
\Delta \varepsilon_{3} & =-\frac{1-\mu}{2 \mu} \Delta \varepsilon_{1} .
\end{aligned}
$$

Considering $\Delta \sigma_{1}=0$ and $\Delta \sigma_{3} \neq 0$ under the lateral unloading zone, substituting (9) into (8) yields

$$
E_{t}=-2 u \frac{\Delta \sigma_{3}}{\Delta \varepsilon_{1}}=2 u E_{0}
$$

$E_{0}$ can be obtained by taking the derivative with respect to the stress-strain curves as follows:

$$
\begin{aligned}
E_{0} & =\frac{d\left(\sigma_{1}-\sigma_{3}\right)}{d \varepsilon_{1}}=\frac{1}{a+b \varepsilon_{1}}-\frac{b \varepsilon_{1}}{\left(a+b \varepsilon_{1}\right)^{2}} \\
& =\frac{a}{\left(a+b \varepsilon_{1}\right)^{2}} .
\end{aligned}
$$

Simplifying (2) yields

$$
\varepsilon_{1}=\frac{a}{1 /\left(\left(\sigma_{1}-\sigma_{3}\right)-\left(3\left(1-K_{0}\right) /\left(1+2 K_{0}\right)\right)\right) \sigma_{m}-b} .
$$

Inserting (12) into (11) yields

$$
E_{0}=\frac{1}{a}\left\{1-b\left[\left(\sigma_{1}-\sigma_{3}\right)-\frac{3\left(1-K_{0}\right)}{1+2 K_{0}} \sigma_{m}\right]\right\}^{2} .
$$

In Section 2, the relationship between initial tangent modulus and confining pressure can be fitted with power functions, which are as follows:

$$
E_{i}=K P_{a}\left(\frac{\sigma_{a}}{P_{a}}\right)^{n},
$$

where $P_{a}$ is the atmospheric pressure and $K$ and $n$ can be calculated by the following equations:

$$
\begin{aligned}
\lg \frac{E_{i}}{P_{a}} & =\lg K+n \lg \frac{\sigma_{a}}{P_{a}} \\
n & =\frac{\Delta \lg \left(E_{i} / P_{a}\right)}{\Delta \lg \left(\sigma_{a} / P_{a}\right)} .
\end{aligned}
$$

By refining $R_{f}$ as failure ratio when parameter $R_{f}<1, R_{f}$ can be calculated through the following formula:

$$
R_{f}=\frac{\left(\sigma_{1}-\sigma_{3}\right)_{f}-\left(3\left(1-K_{0}\right) /\left(1+2 K_{0}\right)\right) \sigma_{m}}{\left(\sigma_{1}-\sigma_{3}\right)_{\mathrm{ult}}-\left(3\left(1-K_{0}\right) /\left(1+2 K_{0}\right)\right) \sigma_{m}} .
$$

Submitting (17) and $a=1 / E_{i}, b=1 /\left(\left(\sigma_{1}-\sigma_{3}\right)_{\mathrm{ult}}-(3(1-\right.$ $\left.\left.K_{0}\right) /\left(1+2 K_{0}\right)\right) \sigma_{m}$ ) into (13), the following equation can be obtained:

$$
\begin{aligned}
E_{0} & =\left[1-R_{f} S\right]^{2} E_{i} \\
S & =\frac{\left(\sigma_{1}-\sigma_{3}\right)-\left(3\left(1-K_{0}\right) /\left(1+2 K_{0}\right)\right) \sigma_{m}}{\left(\sigma_{1}-\sigma_{3}\right)_{f}-\left(3\left(1-K_{0}\right) /\left(1+2 K_{0}\right)\right) \sigma_{m}},
\end{aligned}
$$

where $S$ denotes stress level.

The following equation can be obtained based on the relationship between the Mohr-Coulomb failure criterion and confining pressure:

$$
\frac{\left(\sigma_{1}-\sigma_{3}\right)_{f}}{2}=c \cos \varphi+\frac{\left(\sigma_{1}-\sigma_{3}\right)_{f}}{2} \sin \varphi,
$$

where $c, \varphi$ are cohesion and the effective angle of internal friction under lateral unloading condition, separately. 
For soil under the lateral unloading condition, its destruction deviator stress can be computed as follows:

$$
\left(\sigma_{1}-\sigma_{3}\right)_{f}=\frac{2 \sigma_{r} \sin \varphi+2 c \cos \varphi}{1-\sin \varphi} .
$$

$\sigma_{r}$ is the axial consolidation confining pressure.

By substituting (21) into (19), stress level $S$ can be expressed as follows:

$$
\begin{aligned}
S= & \frac{\left(\sigma_{1}-\sigma_{3}\right)-\left(3\left(1-K_{0}\right) /\left(1+2 K_{0}\right)\right) \sigma_{m}}{\left(2 \sigma_{r} \sin \varphi+2 c \cos \varphi /(1-\sin \varphi)\right)-\left(3\left(1-K_{0}\right) /\left(1+2 K_{0}\right)\right) \sigma_{m}} \\
& =\frac{\left[\left(1+2 K_{0}\right)\left(\sigma_{1}-\sigma_{3}\right)-3\left(1-K_{0}\right) \sigma_{m}\right](1-\sin \varphi)}{2\left(1+2 K_{0}\right)\left(\sigma_{r} \sin \varphi+c \cos \varphi\right)-3\left(1-K_{0}\right)(1-\sin \varphi) \sigma_{m}} .
\end{aligned}
$$

Likewise, $E_{0}$ can be determined by substituting (14) and (22) into (18):

$$
E_{0}=K P_{a}\left(\frac{\sigma_{a}}{P_{a}}\right)^{n}\left\{1-R_{f} \times \frac{\left[\left(1+2 K_{0}\right)\left(\sigma_{1}-\sigma_{3}\right)-3\left(1-K_{0}\right) \sigma_{m}\right](1-\sin \varphi)}{2\left(1+2 K_{0}\right)\left(\sigma_{r} \sin \varphi+c \cos \varphi\right)-3\left(1-K_{0}\right)(1-\sin \varphi) \sigma_{m}}\right\}^{2}
$$

$E_{t}$ can be derived by substituting (23) into (10):

$$
E_{t}=2 \mu K P_{a}\left(\frac{\sigma_{a}}{P_{a}}\right)^{n}\left\{1-R_{f} \times \frac{\left[\left(1+2 K_{0}\right)\left(\sigma_{1}-\sigma_{3}\right)-3\left(1-K_{0}\right) \sigma_{m}\right](1-\sin \varphi)}{2\left(1+2 K_{0}\right)\left(\sigma_{r} \sin \varphi+c \cos \varphi\right)-3\left(1-K_{0}\right)(1-\sin \varphi) \sigma_{m}}\right\}^{2} .
$$

In the case of axial unloading, $\Delta \sigma_{3}=0, E_{0}$ in (4) can be expressed as follows:

$$
E_{0}=\frac{\Delta \sigma_{1}}{\Delta \varepsilon_{1}}
$$

Based on the generalized Hooke's law and (7), the following equation is obtained:

$$
\Delta \varepsilon_{1}=\frac{\Delta \sigma_{1}}{E_{t}}
$$

\section{Comparing (25) with (26) yields}

$$
E_{t}=E_{0} .
$$

The destruction deviator stress under axial unloading can be obtained based on the Mohr-Coulomb failure criterion:

$$
\left(\sigma_{1}-\sigma_{3}\right)_{f}=\frac{-2 \sigma_{a} \sin \varphi-2 c \cos \varphi}{1+\sin \varphi}
$$

where $c, \varphi$ are cohesion and effective angle of internal friction under axial unloading condition, separately.

By substituting (28) into (19), stress level $S$ can be expressed as follows:

$$
\begin{aligned}
S= & \frac{\left(\sigma_{1}-\sigma_{3}\right)-\left(3\left(1-K_{0}\right) /\left(1+2 K_{0}\right)\right) \sigma_{m}}{\left(\left(-2 \sigma_{a} \sin \varphi-2 c \cos \varphi\right) /(1+\sin \varphi)\right)-\left(3\left(1-K_{0}\right) /\left(1+2 K_{0}\right)\right) \sigma_{m}} \\
& =\frac{\left[\left(1+2 K_{0}\right)\left(\sigma_{1}-\sigma_{3}\right)-3\left(1-K_{0}\right) \sigma_{m}\right](1+\sin \varphi)}{-2\left(1+2 K_{0}\right)\left(\sigma_{a} \sin \varphi+c \cos \varphi\right)-3\left(1-K_{0}\right)(1+\sin \varphi) \sigma_{m}} .
\end{aligned}
$$




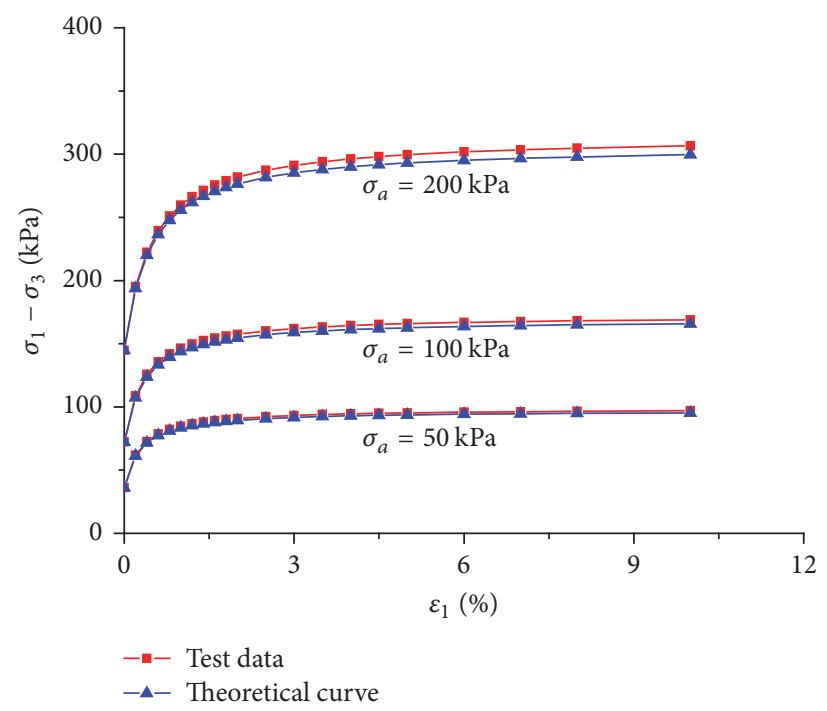

FIGURE 18: Theoretical model versus testing results for mucky soil under lateral unloading condition.

Likewise, $E_{0}$ can be determined by substituting (14) and (29) into (18):

$$
E_{0}=K P_{a}\left(\frac{\sigma_{a}}{P_{a}}\right)^{n}\left\{1-R_{f} \times \frac{\left[\left(1+2 K_{0}\right)\left(\sigma_{1}-\sigma_{3}\right)-3\left(1-K_{0}\right) \sigma_{m}\right](1+\sin \varphi)}{-2\left(1+2 K_{0}\right)\left(\sigma_{a} \sin \varphi+c \cos \varphi\right)-3\left(1-K_{0}\right)(1+\sin \varphi) \sigma_{m}}\right\}^{2} .
$$

$E_{t}$ can be derived by substituting (30) into (27):

$$
E_{t}=K P_{a}\left(\frac{\sigma_{a}}{P_{a}}\right)^{n}\left\{1-R_{f} \times \frac{\left[\left(1+2 K_{0}\right)\left(\sigma_{1}-\sigma_{3}\right)-3\left(1-K_{0}\right) \sigma_{m}\right](1+\sin \varphi)}{-2\left(1+2 K_{0}\right)\left(\sigma_{a} \sin \varphi+c \cos \varphi\right)-3\left(1-K_{0}\right)(1+\sin \varphi) \sigma_{m}}\right\}^{2} .
$$

The expression of the tangent modulus in the DuncanChang model is

$$
E_{t}=K P_{a}\left(\frac{\sigma_{a}}{P_{a}}\right)^{n}\left\{1-R_{f} \frac{\left(\sigma_{1}-\sigma_{3}\right)(1-\sin \varphi)}{2 c \cos \varphi+2 \sigma_{a} \sin \varphi}\right\}^{2}
$$

Comparing (24), (31), and (32), we conclude that variations exist between the three tangent moduli under different stress paths.

\section{Verification for the Tangent Modulus under Unloading}

By substituting (24) and (31) into (10) and (26), respectively, the stress-strain formulas of soils under lateral unloading and axial unloading can be obtained. Figures 18-21 present the comparison between the theoretical curve and test data.

From Figures 18-21, we can conclude that the difference between the theoretical curve and the test data for mucky soil is less than $3 \%$ and that for silty clay is less than $5 \%$. Therefore, the formulas of (24) and (31) can be well applied to the constitutive model of soil, which provides a theoretical basis for accurately predicting the deformation characteristics of soil under different stress paths during excavation.

\section{Conclusions}

(1) The stress-strain curves of soils under different stress paths are obtained by experiments, and the curves exhibit nonlinear quality. However, the development law of axial unloading stress-strain curves clearly differs from that of axial loading and lateral unloading stress-strain curves.

(2) During axial unloading, the failure model of soil does not present compression-shear failure but presents axial elongated failure.

(3) A hyperbola equation on stress-strain relation of soil under unloading is proposed and verified by the experiment. 


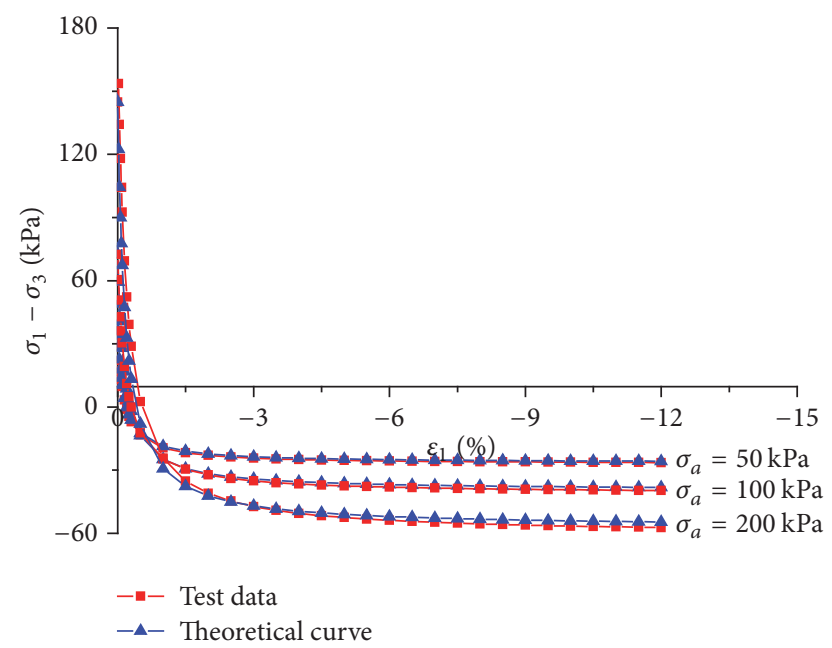

FIgURE 19: Theoretical model versus testing results for mucky soil under axial unloading condition.

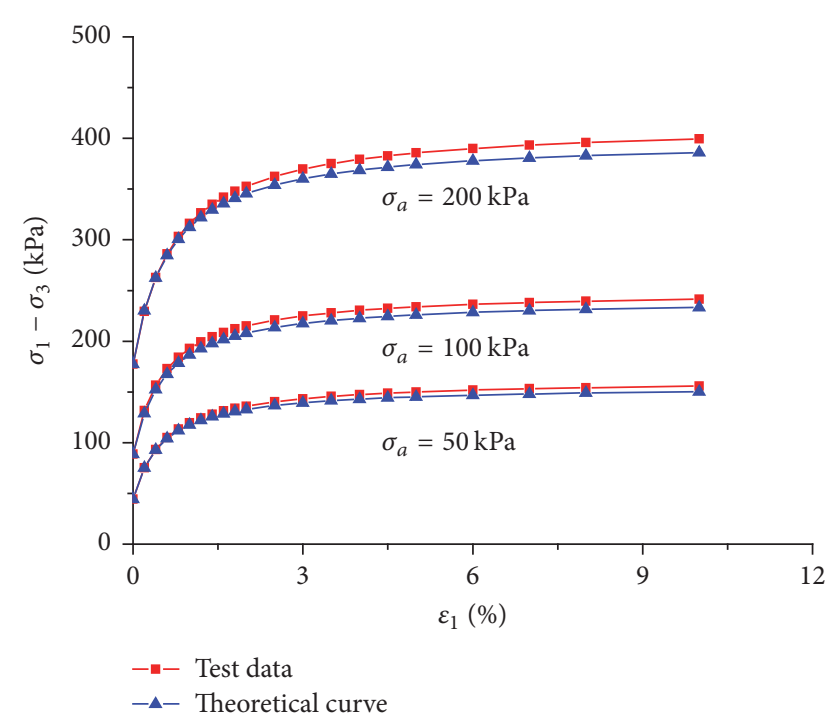

FIgURE 20: Theoretical model versus testing results for silty clay under axial unloading condition.

(4) For the same type of soil, the initial tangent modulus of soil increases with the consolidation pressure. The relationship between initial tangent modulus and confining pressure under unloading can be fitted with power functions.

(5) With the analysis of the test results as basis, the tangent modulus formulas of soil with the actual stress paths under lateral unloading and axial unloading in the foundation pit are deduced by revising the Duncan-Chang model.

(6) Calculation results of theoretical model under unloading condition are found to be in good agreement with test results.

\section{Data Availability}

The data used to support the findings of this study are available from the corresponding author upon request.

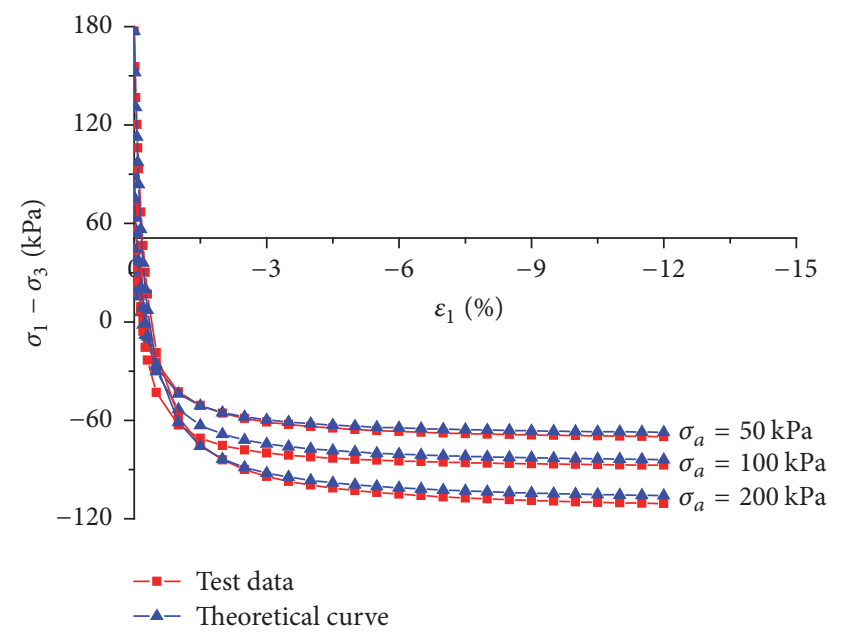

FIGURE 21: Theoretical model versus testing results for silty clay under axial unloading condition.

\section{Conflicts of Interest}

The authors declare that there are no conflicts of interest regarding the publication of this paper.

\section{Acknowledgments}

The authors would like to acknowledge the financial supports of the Project of a Special Fund for the Basic Scientific Research Service of the Central University (Grants nos. 310828173401 and 310828173702 ).

\section{References}

[1] J. H. Atkinson, D. Richardson, and S. E. Stallebrass, "Effect of recent stress history on the stiffness of overconsolidated soil," Géotechnique, vol. 40, no. 4, pp. 531-540, 1990.

[2] J.-H. Yin, F. Saadat, and J. Graham, "Constitutive modelling of a compacted sand-bentonite mixture using three-modulus hypoelasticity," Canadian Geotechnical Journal, vol. 27, no. 3, pp. 365-372, 1990

[3] V. Malandraki and D. G. Toll, "Drained probing triaxial tests on a weakly bonded artificial soil," Géotechnique, vol. 50, no. 2, pp. 141-151, 2000.

[4] V. Malandraki and D. G. Toll, "Triaxial tests on weakly bonded soil with changes in stress path," Journal of Geotechnical and Geoenvironmental Engineering, vol. 127, no. 3, pp. 282-291, 2001.

[5] B. Xiang, Z. L. Zhang, S. C. Chi, and G. Lin, "Study of constitutive relations of rock fill under complex stress path," Rock and Soil Mechanics, vol. 31, no. 6, pp. 1716-1723, 2010.

[6] M. C. Weng, F. S. Jeng, Y. M. Hsieh, and T. H. Huang, "A simple model for stress-induced anisotropic softening of weak sandstones," International Journal of Rock Mechanics and Mining Sciences, vol. 45, no. 2, pp. 155-166, 2008.

[7] C. W. W. Ng, "Stress paths in relation to deep excavations," Journal of Geotechnical and Geoenvironmental Engineering, vol. 125, no. 5, pp. 357-363, 1999.

[8] Y. Hong, C. H. Koo, C. Zhou, C. W. W. Ng, and L. Z. Wang, "Small strain path-dependent stiffness of toyoura sand: Laboratory measurement and numerical implementation," 
International Journal of Geomechanics, vol. 17, no. 1, pp. 1-10, 2017.

[9] Y. G. Zhang, K. Y. Zhang, W. L. Li, and Q. Z. Shi, "Unloading triaxial experimental study on stress path of excavated soil slope," Advanced Materials Research, vol. 243-249, pp. 27972801, 2011.

[10] T. W. Lambe and W. A. Marr, "Stress path method: Second edition," Journal of Geotechnical and Geoenvironmental Engineering, vol. 105, no. 6, pp. 727-738, 1979.

[11] E. Bilotta and S. E. Stallebrass, "Prediction of stresses and strains around model tunnels with adjacent embedded walls in overconsolidated clay," Computers \& Geosciences, vol. 36, no. 6, pp. 1049-1057, 2009.

[12] M. Karstunen and Z.-Y. Yin, "Modelling time-dependent behaviour of Murro test embankment," Géotechnique, vol. 60, no. 10, pp. 735-749, 2010.

[13] L. R. Hoyos, D. D. Pérez-Ruiz, and A. J. Puppala, "Modeling unsaturated soil response under suction-controlled true triaxial stress paths," International Journal of Geomechanics, vol. 12, no. 3, pp. 292-308, 2012.

[14] C. Chen and J. Zhang, "Constitutive modeling of loose sands under various stress paths," International Journal of Geomechanics, vol. 13, no. 1, pp. 1-8, 2013.

[15] R. J. Jardine, Investigations of Pile-Soil Behavior, with Special Reference to the Foundations of Offshore Structures, Imperial College, London, UK, 1985.

[16] A. Al-Tabbaa and D. M. Wood, "An experimentally based 'bubble' model for clay," in Proceedings of the 3rd International Symposium on Numerical Models in Geomechanics, pp. 91-99, Niagara Falls, Canada, May, 1989.

[17] R. J. Mair, "Developments in geotechnical engineering research: application to tunnels and deep excavations," Journal of Periodontology, vol. 93, no. 1, pp. 27-41, 1993.

[18] S. E. Stallebrass and R. N. Taylor, "The development and evaluation of a constitutive model for the prediction of ground movements in overconsolidated clay," Géotechnique, vol. 47, no. 2, pp. 235-253, 1997.

[19] J. M. Duncan and C. Y. Chang, "Nonlinear analysis of stress and strain in soils," ASCE Soil Mechanics and Foundation Division Journal, vol. 96, no. 5, pp. 1629-1653, 1970.

[20] J. Chen, D. Jiang, S. Ren, and C. Yang, "Comparison of the characteristics of rock salt exposed to loading and unloading of confining pressures," Acta Geotechnica, vol. 11, no. 1, pp. 221-230, 2016.

[21] D. Masin, "Clay hypoplasticity model including stiffness anisotropy," Géotechnique, vol. 64, no. 3, pp. 232-238, 2014.

[22] D. Masin and J. Rott, "Small strain stiffness anisotropy of natural sedimentary clays: review and a model," Acta Geotechnica, vol. 9, no. 2, pp. 299-312, 2014.

[23] H. Chen, G. X. Mei, and Z. Li, "Deformation characteristics of the soil around the foundation pit with lateral unloading," Journal of Hefei University of Technology, vol. 32, no. 10, pp. 15511553, 2009.

[24] S. Li, "Modulus formula for foundation soil under lateral unloading during excavation," China Civil Engineering Journal, vol. 35 , no. 5, pp. 70-74, 2002.

[25] S.-X. He, G.-S. Han, X.-S. Zhuang, and X.-G. Wu, "Experimental researches on unloading deformation of clay in excavation of foundation pit," Rock and Soil Mechanics, vol. 24, no. 1, pp. 17-20, 2003.
[26] L. Liu, H. Zhang, and Y. Li, "Influence of the side of soil deformation on the excavation of foundation pit," Journal of Beijing Jiaotong University, vol. 37, no. 4, pp. 98-102, 2013. 


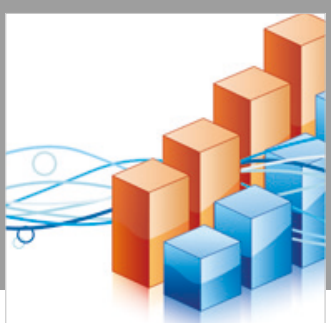

Advances in

Operations Research

\section{-n-m}
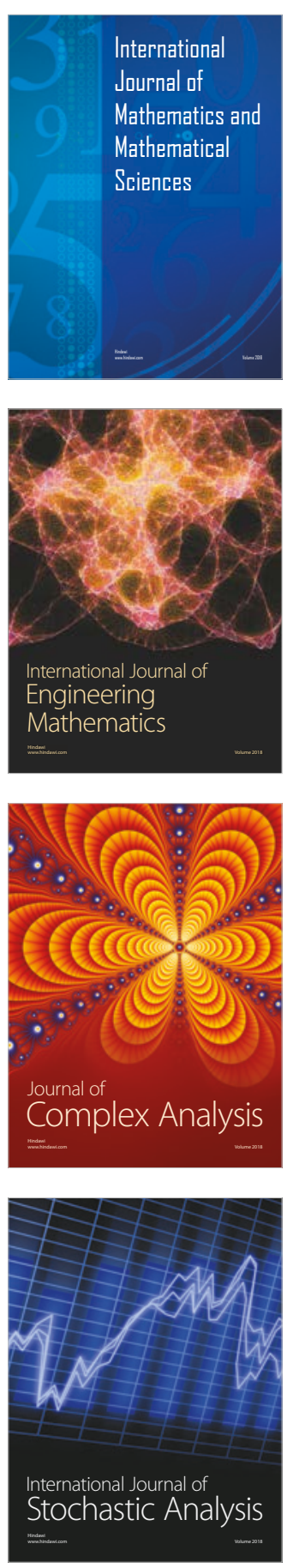
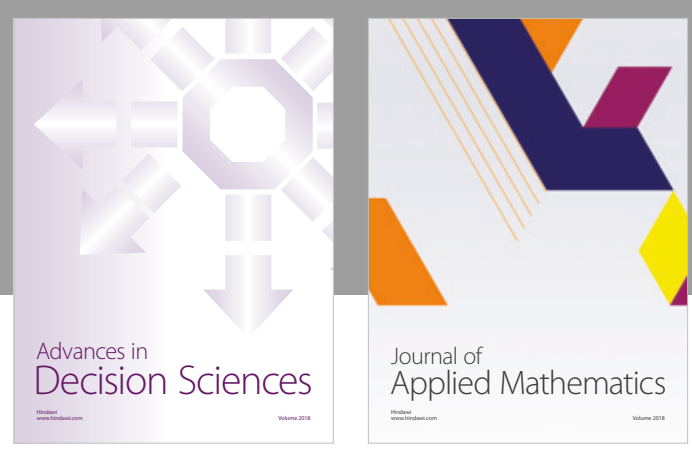

Journal of

Applied Mathematics
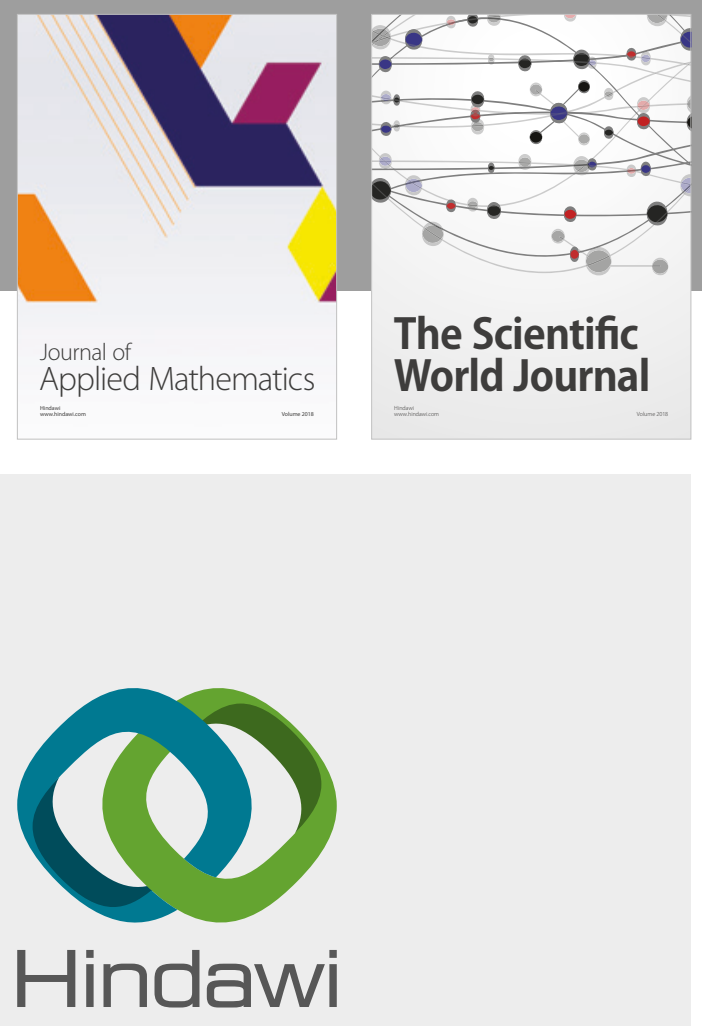

Submit your manuscripts at

www.hindawi.com

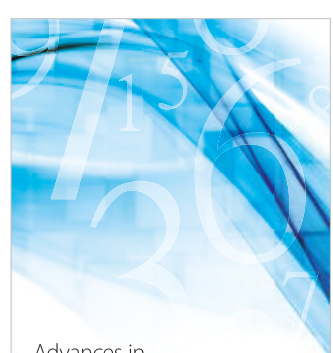

Advances in
Numerical Analysis
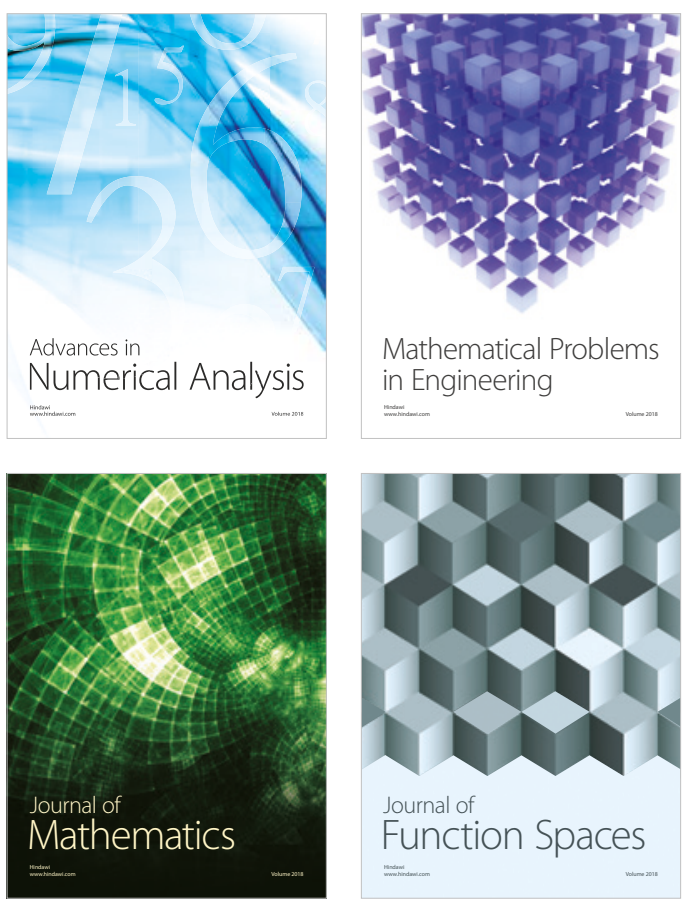

Mathematical Problems in Engineering

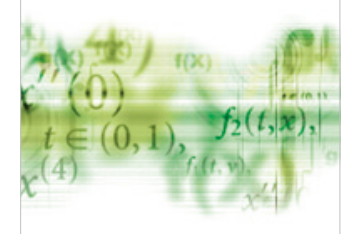

International Journal of

Differential Equations

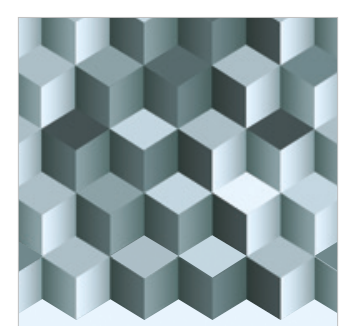

Journal of

Function Spaces

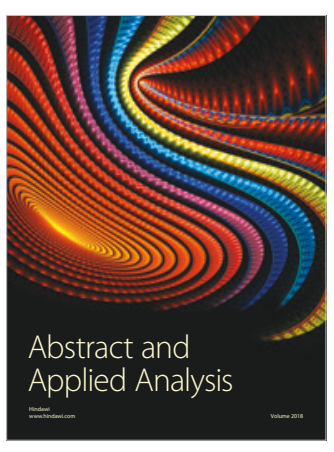

The Scientific

World Journal

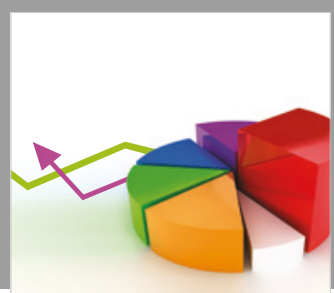

Journal of

Probability and Statistics
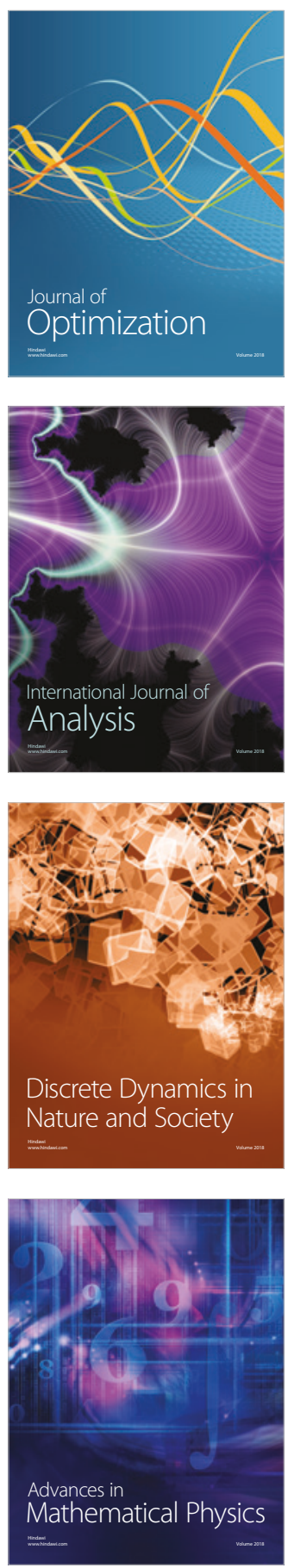